Federal Reserve Bank of Minneapolis

Research Department Staff Report 512

May 2015

\title{
Macroeconomic Volatility and External Imbalances
}

\author{
Alessandra Fogli \\ Federal Reserve Bank of Minneapolis and CEPR \\ Fabrizio Perri \\ Federal Reserve Bank of Minneapolis, \\ NBER, and CEPR
}

\begin{abstract}
Does macroeconomic volatility/uncertainty affect accumulation of net foreign assets? In OECD economies over the period 1970-2012, changes in country specific aggregate volatility are, after controlling for a wide array of factors, significantly positively associated with net foreign asset position. An increase in volatility (measured as the standard deviation of GDP growth) of $0.5 \%$ over period of 10 years is associated with an increase in the net foreign assets of around 8\% of GDP. A standard open economy model with time varying aggregate uncertainty can quantitatively account for this relationship. The key mechanism is precautionary motive: more uncertainty induces residents to save more, and higher savings are in part channeled into foreign assets. We conclude that both data and theory suggest uncertainty/volatility is an important determinant of the medium/long run evolution of external imbalances in developed countries.
\end{abstract}

Keywords: Business cycles; Current account; Global imbalances; Precautionary saving; Uncertainty JEL classification: F32, F34, F41

\footnotetext{
*This manuscript has been accepted for publication in Journal of Monetary Economics. The manuscript will undergo copyediting, typesetting, and review of the resulting proof before it is published in its final form. Please note that during the production process, errors may be discovered which could affect the content, and all disclaimers that apply to the journal apply to this manuscript. A definitive version was subsequently published in Journal of Monetary Economics [Vol. 69 (January 2015)], DOI 10.1016/j.jmoneco.2014.11.005.

We are grateful to Ctirad Slavik, Enoch Hill, and especially Alberto Polo for outstanding research assistance. Thanks to Javier Bianchi, Daniele Siena and Cedric Tille for insightful discussions, and to seminar participants at several institutions and conferences for helpful comments. We also thank the European Research Council for financial support under Grant 313671 - RESOCONBUCY. Data and codes used in this paper are available on the authors' websites. The views expressed herein are those of the authors and not necessarily those of the Federal Reserve Bank of Minneapolis or the Federal Reserve System.
} 


\section{Introduction}

The main contribution of this paper is to show that time varying uncertainty about macroeconomic conditions (which throughout the paper we will measure as realized macro volatility) is a quantitatively important determinant of domestic consumption and saving decisions and, through these channels, of the medium and long run evolution of net foreign asset positions of countries.

The paper first shows that when countries become more volatile than their partners, they tend to run current account surpluses. In particular, for OECD countries over the last 40 years, changes in relative macroeconomic volatility (measured as the standard deviation

of GDP growth of a country over a 10 year window, relative to the same measure in other OECD countries) are significantly positively associated with changes in net foreign asset position. Quantitatively, an increase in relative volatility of $0.5 \%$ over a 10 years period (a change experienced by many countries in our sample) is associated with a change in net foreign asset position of about $8 \%$ of GDP. This relation is robust to the inclusion of a wide array of controls, such as growth, various measures of macroeconomic policy, and demographic conditions.

We then introduce time varying macroeconomic uncertainty in a standard open economy macro model, and show that a calibrated version of the model can account for this relationship well, both in the medium and in the long run. The intuition is simple: in response to increases in domestic uncertainty agents increase their precautionary saving balances. Decreasing returns in domestic capital, increasing risk of domestic capital (arising from the increase in uncertainty) and the assumption of open economy imply that the bulk of the additional precautionary saving will go into foreign assets. If changes in uncertainty are persistent, the accumulation of foreign assets continues through time and can lead to sizeable changes in medium/long run net foreign asset positions, thus generating persistent "global imbalances".

Our findings suggest that time varying uncertainty, which many authors have recently put at the center stage of macroeconomic analysis, is an especially important factor in the context of open economies. To give a more concrete example, consider two countries that have experienced large external imbalances of opposite sign, the United States and Japan. During the period 1980-2010 the United States has experienced a reduction of its foreign position of about $25 \%$ of its GDP and at the same time its macro volatility (relative to 
those of other OECD countries) has declined by roughly 40 basis points. Over the same period Japan witnessed an increase in net foreign asset (henceforth NFA) of about 50\%, together with an increase in relative volatility of about 100 basis points. According to our framework the changes in relative volatility in the two countries can account for a fraction between $1 / 4$ and $1 / 3$ of the respective imbalances. The model is also useful to precisely understand and quantify the channels through which uncertainty affects agents' decisions, and to understand how the effects of uncertainty depend on structural aspects of the economy, such as preferences, persistence of shocks and the development of international financial markets.

This paper is related to various strands of literature. The first studies the issue of "global imbalances" and searches for causes of the growing dispersion of external imbalances in various countries. ${ }^{1}$ Our study is the first to show empirically and theoretically that macroeconomic volatility is a major systematic factor in explaining the evolution of external imbalances in a large cross section of countries. The second is the rapidly growing literature that studies the effect of changes in macroeconomic uncertainty on aggregate outcomes. ${ }^{2}$ Most of this literature focuses on the importance of shocks to uncertainty in generating business cycle fluctuations, whereas our work focuses on external positions and show that even in the case where shocks to uncertainty have a modest business cycle impact, they can have a sizeable impact on external positions of countries over the medium/long run. A recent paper that studies the impact of volatility in open economies is the work of Gourio et al. (2014), which mostly focuses on the impact of volatility on gross external positions. Finally, our work is also connected to the literature that studies how the optimal level of external reserves of a country is determined by precautionary motives in an environment with aggregate risk. ${ }^{3}$

The paper is organized as follows. Section 2 provides empirical evidence on the relationship between volatility of output growth and external imbalances. Section 3 presents the model, and Section 4 discusses the results. Section 5 concludes.

\footnotetext{
${ }^{1}$ See, among others, Fogli and Perri (2006), Blanchard (2007), Caballero, Fahri and Gourinchas (2008), Backus et al (2009), Mendoza, Quadrini and Rios-Rull (2009), Broer (2012), Prades and Rabitsch (2012), and Chang, Kim and Lee (2013)

${ }^{2}$ See, among others, Barlevy (2004), Basu and Bundick (2012), Justiniano and Primiceri (2008), Bloom (2009), Fernández-Villaverde et al. (2011), Bloom et al. (2012), Arellano, Bai and Kehoe (2012), and Schaal (2012).

${ }^{3}$ See, for example, Bianchi et al (2012), Durdu, Mendoza and Terrones (2007), Hur and Kondo (2013), and Jeanne and Ranciere (2011).
} 


\section{Empirical evidence}

This section first establishes that for developed countries changes in (relative) macroeconomic volatility are positively associated with changes in NFA. This relationship constitutes our key piece of evidence about the role of precautionary motives in determining inter-temporal trade patterns across countries.

Our sample consists of the set of all OECD countries for which we could obtain comparable (across time and countries) macroeconomic data starting at least in the early 1980s. The final dataset is an unbalanced panel that includes 20 countries and spans from the first quarter of 1970 to the last quarter of $2012 .^{4}$

Our benchmark measure of relative macroeconomic volatility for a country in a given time interval is the standard deviation of quarterly real GDP growth over the interval minus the average (across the other countries) standard deviation of quarterly real GDP growth over the interval. ${ }^{5}$ Our benchmark measure of net foreign asset position is total gross foreign assets minus total gross foreign liabilities over GDP, averaged over the same interval. Figure 1 provides a comprehensive summary of our dataset, plotting trends of net foreign asset position and relative volatility of GDP growth in each year for all countries in our sample.

\footnotetext{
${ }^{4}$ All the national accounts data are from the OECD Quarterly National Accounts. The foreign asset position data up to 2007 is from Lane and Milesi-Ferretti (2007), and figures in post 2007 years are derived from the IMF international investment position statistics. The set of countries in our dataset, with country acronyms and sample span in parenthesis, is as follows: Australia (AUS, 1970.1 - 2012.4), Austria (AUT, 1976.1 - 2012.4), Belgium (BEL, 1980.1 - 2012.4), Canada (CAN, 1970.1 - 2012.4), Switzerland (CHE, 1980.1 - 2012.4), Germany (DEU, 1970.1 - 2012.4), Denmark (DNK, 1977.1 2012.4), Spain (ESP, 1970.1 - 2012.4), Finland (FIN, 1975.1 - 2012.4), France (FRA, 1970.1 - 2012.4), United Kingdom (GBR, 1970.1 - 2012.4 ), Greece (GRC, 1970.1 - 2011.1), Italy (ITA, 1970.1 - 2012.4), Japan (JAP, 1970.1 - 2012.4), Korea (KOR, 1970.1 - 2012.4), Mexico (MEX, 1980.1 -2012.4), Netherlands (NED, 1977.1 - 2012.4), Norway ( NOR, 1978.1 - 2012.4), Sweden (SWE, 1980.1 - 2012.4), United States (USA, 1970.1 - 2012.4)

${ }^{5}$ More precisely $\sigma_{i, t}$, i.e. macroeconomic volatility in country $i$ and year $t$ is measured as follows. Let $s(t)$ be the first quarter of year $t$ and let $g_{i, s}$ be the log difference of real GDP of country $i$ between quarter $s$ and quarter $s-1$. Volatility is

$$
\sigma_{i, t}=\left(\sum_{j=-20}^{+20} g_{i, s(t)+j}^{2}-\bar{g}_{i, s(t)}\right)^{\frac{1}{2}}
$$
}

where $\bar{g}_{i, s(t)}=\frac{1}{41} \sum_{j=-20}^{+20} g_{i, s(t)+j}$. Note that volatility is computed only for years/countries that have at least 21 quarterly observations for growth $g_{i, s(t)+j}$. Relative volatility $\sigma_{i, t}^{R}$ is then measured as

$$
\sigma_{i, t}^{R}=\sigma_{i t}-\frac{1}{N(t)} \sum_{j \neq i} \sigma_{j, t}
$$

where $N(t)$ indicates the number of countries that have an observation for volatility in year $t$. 
Both measures are computed in each year using 10 years rolling windows (always using quarterly data for volatility and yearly data for NFA position), where the time indicator in each graph represents the mid year of the window.

Note first how many countries in our sample experience changes in relative volatility (measured on the right scale) of the order of 50 basis points or bigger. More importantly Figure 1 reveals that for many countries there is a strong association between medium/long run changes in their relative volatility and changes in the net external position. Countries which experienced a long run reduction of their relative volatility/uncertainty (such as Australia, Austria, the United Kingdom and Greece) have also experienced a long run fall in their external asset position. Countries who have instead experienced a long run increase in their relative volatility (such as Belgium, Switzerland and Japan) have accumulated foreign assets. Obviously the relation does not hold perfectly for every country, suggesting that there are other factors driving the accumulation/decumlation of foreign assets, but the figure is consistent with the idea that changes in volatility plays an important role in affecting foreign asset dynamics.

The association between the variables that appear in Figure 1 might be driven by any common factor that affects, at the same time, volatility and net foreign asset position. In order to control for these factors, we next turn to linear regression analysis. Table 1 reports the coefficients obtained regressing the benchmark measure of NFA (averaged over 10 years windows) on volatility (computed as the standard deviation of GDP growth over the same window) and on many different sets of controls. All regressions include country and year fixed effects. ${ }^{6}$ Country fixed effects control for the possibility that unobserved characteristics of a country (for example quality of institutions) drive at the same time long run volatility and external imbalances. Time fixed effects capture events that might affect the NFA of all countries at the same time. Both country and time fixed effects are always significant reflecting the importance of country specific factors and of common time factors (such as financial globalization or the growing importance of new industrial nations not in our dataset, such as China or India). The next control (in specifications (ii) through (viii)) is average GDP growth over the window. If high growth periods are also low volatility periods

\footnotetext{
${ }^{6}$ We have experimented with using as independent variable both volatility and relative volatility (i.e. volatility minus foreign volatility). Because of the time fixed effects, and because foreign volatility in each period is very similar for all countries in the sample (hence similar to a time fixed effect), regression coefficients and standard errors are extremely close under the two choices; tables 1 and 2 report the coefficient using volatility as regressor
} 

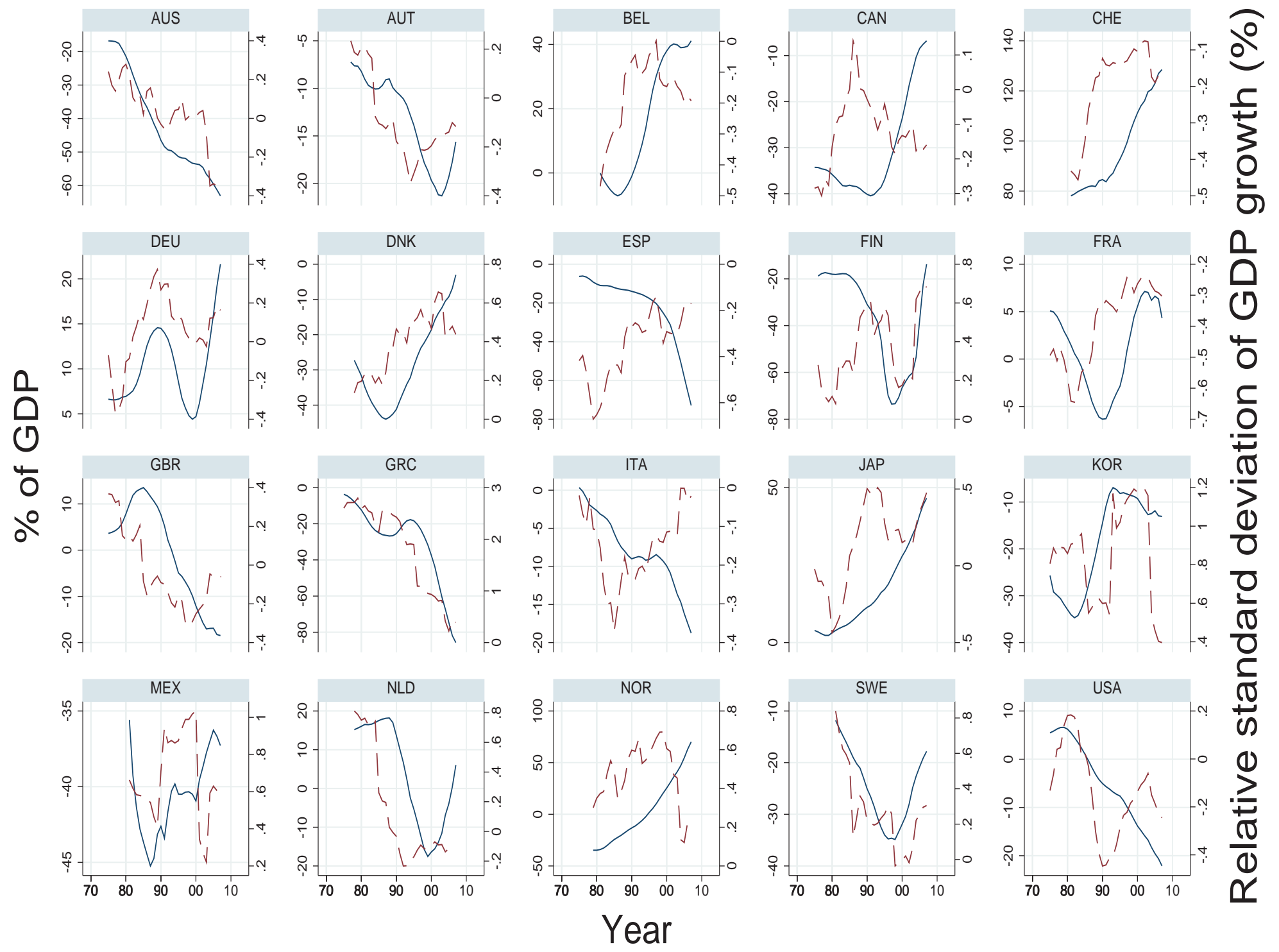

\section{Net foreign asset position $\quad-----$ Relative volatility}

Figure 1: Relative volatility and net foreign asset positions 
(as it has been documented, for example, by Ramey and Ramey, 1995), and high growth induces countries to borrow on international markets to finance investment, then a positive relation between volatility and NFA would emerge, but not for precautionary reasons. Note that the coefficient on growth is negative, as expected, and sometimes significant. When growth is included the coefficient of volatility is reduced a bit (from 19.9 to 16.4) but it remains large and significant. Additional controls (in specifications (iii) through (viii) in Table 1) include average inflation, standard deviation of inflation, standard deviation of real government consumption growth, a measure of trade openness and two measures of financial openness. The first measure is gross international financial diversification (foreign assets plus foreign liabilities over GDP) while the second measure is the Chinn-Ito index of financial openness. All the controls are constructed computing moments of the relevant variable on the same 10 year window over which NFA is computed. The rationale for including these controls is the possibility that policies (such us monetary or fiscal policy or financial liberalizations) could affect at the same time volatility and imbalances. The numbers in table 1 show that these controls are never significant. The final two controls, in specifications (vii) and (viii), are the share of the population between age 15 and 29 (Share Young) and the share of the population over 65 (Share old). Many papers (see, for example, Domeij and Floden, 2006) have shown that demographic structure is an important determinant of NFA. Recent work by Jaimovich and Siu (2009) argues that for G7 countries demographic structure might have an effect on macroeconomic volatility. These two findings together suggest that the link between NFA and volatility could be driven by changes in the demographic structure. The numbers in Table 1 show that changes in demographic structure are not significant, so they do not appear to be important to explain the connection between volatility and NFA. Overall Table 1 suggests that, even after controlling for a very wide range of factors, the volatility of GDP growth is always significantly (at the $1 \%$ or $5 \%$ level in all specifications) associated with the net foreign asset position of a country. 


\section{Table 1: Volatility and External Imbalances}

Dependent variable is Net Foreign Assets over GDP

\begin{tabular}{|c|c|c|c|c|c|c|c|c|}
\hline Regressor & (i) & (ii) & (iii) & (iv) & $(\mathrm{v})$ & (vi) & (vii) & (viii) \\
\hline \multirow[t]{2}{*}{ Volatility of GDP Growth } & $19.9^{* * *}$ & $16.4^{* * *}$ & $16.4^{* * *}$ & $16.5^{* *}$ & $14.0^{* *}$ & $15.3^{* *}$ & $15.0^{* *}$ & \\
\hline & $(3.7)$ & $(4.8)$ & $(4.5)$ & $(6.5)$ & $(5.9)$ & $(5.4)$ & $(5.3)$ & \\
\hline \multirow[t]{2}{*}{ Average GDP Growth } & & $-13.5^{*}$ & $-12.7^{*}$ & $-13.8^{*}$ & $-17.1^{*}$ & -12.1 & -17.6 & $-25.7^{* *}$ \\
\hline & & $(7.1)$ & $(7.1)$ & $(7.5)$ & $(8.3)$ & $(8.4)$ & $(9.6)$ & $(10.1)$ \\
\hline \multirow[t]{2}{*}{ Average Inflation } & & & 1.0 & 2.7 & 2.9 & 2.1 & 3.1 & 2.7 \\
\hline & & & $(1.6)$ & $(1.7)$ & $(2.1)$ & $(2.0)$ & $(2.1)$ & $(2.3)$ \\
\hline \multirow[t]{2}{*}{ Volatility of Inflation } & & & -0.3 & -1.4 & -1.2 & -1.0 & -1.6 & -0.6 \\
\hline & & & $(3.4)$ & $(3.3)$ & $(3.1)$ & $(3.1)$ & $(3.0)$ & $(3.3)$ \\
\hline \multirow[t]{2}{*}{ Volatility of Govmt. Cons. Growth } & & & & -5.5 & -8.2 & -7.9 & -6.7 & -9.0 \\
\hline & & & & $(5.0)$ & $(5.5)$ & $(5.6)$ & $(5.4)$ & $(5.7)$ \\
\hline \multirow[t]{2}{*}{ Financial Openness 1} & & & & & 0.8 & 1.3 & 0.3 & 0.9 \\
\hline & & & & & $(3.7)$ & $(4.1)$ & $(4.5)$ & $(4.7)$ \\
\hline \multirow[t]{2}{*}{ Financial Openness 2} & & & & & 2.8 & 1.7 & 1.6 & 2.1 \\
\hline & & & & & $(4.9)$ & $(4.3)$ & $(4.2)$ & $(4.2)$ \\
\hline \multirow[t]{2}{*}{ Trade Openness } & & & & & & -5.7 & -4.7 & -3.8 \\
\hline & & & & & & $(6.4)$ & $(5.9)$ & $(6.1)$ \\
\hline \multirow[t]{2}{*}{ Share Young } & & & & & & & 1.6 & 1.9 \\
\hline & & & & & & & $(1.3)$ & $(1.4)$ \\
\hline \multirow[t]{2}{*}{ Share Old } & & & & & & & -2.2 & -2.1 \\
\hline & & & & & & & $(3.0)$ & $(3.0)$ \\
\hline$N$ & 623 & 623 & 623 & 607 & 597 & 597 & 597 & 597 \\
\hline adj. $R^{2}$ & 0.82 & 0.83 & 0.83 & 0.83 & 0.82 & 0.82 & 0.83 & 0.82 \\
\hline
\end{tabular}

All regressions include country and year fixed effects. Robust standard errors, clustered at the country level, are in parentheses.

${ }^{*} p<0.10,{ }^{* *} p<0.05,{ }^{* * *} p<0.01$ 
Table 2 investigates the robustness of the results to alternative way of computing volatility of GDP growth and to changes in the sample. Columns (i) through (iv) report results for variables (including volatility) over 5 and 20 years windows, as opposed to 10, as in the baseline case. Notice how the coefficients on volatility are always significant and how their magnitude is increasing with the length of the window. In columns (v) and (vi) we regress net foreign asset position (computed on a 10 years window) on volatility computed on a window of the same length, but lagged 5 years. The idea here is that net foreign asset position is a stock variable (cumulated current accounts); if volatility affect current account then volatility might have the its strongest effect not on current but on future NFA. Indeed, we find that this is the case. More precisely the only difference between specification (ii) in Table 1 and specification (vi) in Table 2 is that the first uses contemporaneous volatility while the latter uses lagged volatility. The coefficient on lagged volatility is 20.9 whereas the one on contemporaneous volatility is 16.4 . Section 4.3 will show how both an increase of the size of the coefficient with the length of the window, as well as a larger coefficient on lagged volatility are consistent with the proposed mechanism.

Columns (vii) and (viii) in Table 2 use the volatility of GDP growth obtained by estimating a univariate $\operatorname{GARCH}(1,1)$ on quarterly GDP growth and then taking yearly averages of the quarterly series of conditional standard deviation resulting from the GARCH. Notice that the coefficient on volatility is still significant, although smaller than in previous specifications. Possibly this is due to the presence of high frequency variation in the volatility estimated from the GARCH, which is not associated with high frequency variation in net foreign asset position. This result suggests that an important fraction of the association between volatility and net foreign asset positions happens at medium low frequencies.

The last two columns of Table 2 restrict the sample to include only data from 19852012, a period of lower business cycles volatility and higher financial integration. Results show that even in this more recent period the positive association between net foreign asset position and volatility still holds and has similar magnitude.

We have also experimented with including all the additional controls from table 1 in the different specifications in table 2 and found that their inclusion in the regressions in Table 2 never makes the coefficient on volatility insignificant and it never alters its magnitude by much. 


\section{Table 2: Volatility and External Imbalances - Alternative Measures and Sample}

Dependent variable is Net Foreign Assets $^{a}$

\begin{tabular}{|c|c|c|c|c|c|c|c|c|c|c|}
\hline Regressor & (i) & (ii) & (iii) & (iv) & $(\mathrm{v})$ & (vi) & (vii) & (viii) & (ix) & $(\mathrm{x})$ \\
\hline Vol. Growth & $14.1^{* * *}$ & $12.8^{* *}$ & & & & & & & & \\
\hline (5 yrs) & $(4.4)$ & $(4.6)$ & & & & & & & & \\
\hline Av. Growth & & -6.7 & & & & & & & & \\
\hline$(5 \mathrm{yrs})$ & & $(4.7)$ & & & & & & & & \\
\hline Vol. Growth & & & $24.6^{* * *}$ & $20.9^{* * *}$ & & & & & & \\
\hline (20 yrs) & & & $(6.3)$ & $(6.7)$ & & & & & & \\
\hline Av. Growth & & & & $-18.7^{* *}$ & & & & & & \\
\hline$(20 \mathrm{yrs})$ & & & & $(7.3)$ & & & & & & \\
\hline Vol. Growth & & & & & $22.9^{* * *}$ & $20.7^{* *}$ & & & & \\
\hline (Lagged 5 yrs) & & & & & $(6.4)$ & $(7.3)$ & & & & \\
\hline \multirow{2}{*}{ Av. Growth } & & & & & & -9.4 & & & & \\
\hline & & & & & & $(7.1)$ & & & & \\
\hline Vol. Growth & & & & & & & $13.8^{* *}$ & $13.9^{* *}$ & & \\
\hline (GARCH) & & & & & & & $(5.2)$ & $(5.4)$ & & \\
\hline Av. Growth & & & & & & & & 0.5 & & \\
\hline$(1 \mathrm{yr})$ & & & & & & & & $(2.1)$ & & \\
\hline Vol. Growth & & & & & & & & & $18.5^{* * *}$ & $15.7^{* *}$ \\
\hline$(1985-2012)$ & & & & & & & & & $(4.9)$ & $(6.0)$ \\
\hline Av. Growth & & & & & & & & & & -9.0 \\
\hline (1985-2012) & & & & & & & & & & $(8.1)$ \\
\hline$N$ & 672 & 672 & 460 & 460 & 556 & 556 & 767 & 767 & 460 & 460 \\
\hline adj. $R^{2}$ & 0.76 & 0.77 & 0.92 & 0.93 & 0.85 & 0.85 & 0.69 & 0.69 & 0.86 & 0.86 \\
\hline
\end{tabular}

${ }^{a}$ NFA in each specification are computed on a window of the same length as the window on which volatility is computed.

All regressions include country and year fixed effects. Robust standard errors, clustered at the country level, are in parentheses.

${ }^{*} p<0.10,{ }^{* *} p<0.05, * * * p<0.01$

The main take-away of this section is that for OECD countries there is a robust, economically and statistically significant positive association, over the medium/long run, between 
changes in country specific volatility and changes in net foreign asset position. Quantitatively, a change in the volatility of a given country of the order of $0.5 \%$ (which many countries in our sample have experienced) over a ten year period is associated with a change in NFA of around $8 \%$ of GDP. The next section will discuss how such a link arises naturally in a simple open economy model of consumption/saving/investment decisions, and assess whether the link generated by the model is quantitatively consistent with the link measured in the data.

\section{Model}

Consider a version of the standard one-good, two-country real business cycle model (as Backus, Kehoe Kydland, 1992 or Baxter and Crucini, 1995), extended to allow holdings of foreign stocks and time varying business cycle volatility. In the model agents face persistent country specific productivity shocks and in general international financial markets do not allow perfect insurance of country specific risk; this implies that agents in both countries have a precautionary saving motive. If the volatility of shocks changes over time and across countries, the precautionary motive also changes and this naturally generates, in an open economy equilibrium, external imbalances, with the more volatile country accumulating a net positive external position vis-a-vis the less volatile one. This model has a natural link between changes in volatility and changes in imbalances, and is a good laboratory to check whether precautionary saving motive can account for the observed association between volatilities and imbalances.

The world economy consists of two equal size countries, $i=1,2$, each inhabited by a large number of infinitely-lived consumers and endowed with a constant returns to scale production technology operated by competitive firms. Time is discrete and each period is a quarter. The countries produce a single good, and their preferences and technology have the same structure and parameter values. The labor input consists only of domestic labor, and production is subject to country-specific technology shocks.

In each period $t$, the economy experiences one of finitely many events $s_{t}$. Denote by $s^{t}=\left(s_{0}, \ldots, s_{t}\right)$ the history of events up through and including period $t$. The probability, as of period zero, of any particular history $s^{t}$ is $\pi\left(s^{t}\right)$. Assume that idiosyncratic risk within each country is perfectly insured among residents, so that there is a representative consumer 
in each country who has preferences of the form

$$
\sum_{t=1}^{\infty} \sum_{s^{t}} \beta^{t} \pi\left(s^{t}\right) U\left(c_{i}\left(s^{t}\right), l_{i}\left(s^{t}\right)\right)
$$

where $c_{i}\left(s^{t}\right)$ and $l_{i}\left(s^{t}\right)$ denote consumption and labor of the representative consumer in country $i$ after history $s^{t}, U(c, l)$ is a standard utility function and $\beta>0$ is a positive parameter capturing their rate of time preference. The representative agents in the two countries are endowed with one unit of time per period, and they supply labor to domestic firms in exchange for a wage $w_{i}\left(s^{t}\right)$, own (exogenously given) shares of foreign firms $\lambda$ and a share of domestic firms $1-\lambda$, trade internationally an uncontingent default-free bond $b_{i}\left(s^{t}\right)$ which pays a gross interest $R\left(s^{t}\right)$ and choose consumption in each state of the world to maximize their expected lifetime utilities, given in (1) subject to the following budget constraints:

$$
\begin{aligned}
& c_{1}\left(s^{t}\right)+b_{1}\left(s^{t}\right) \leq l_{1}\left(s^{t}\right) w_{1}\left(s^{t}\right)+(1-\lambda) d_{1}\left(s^{t}\right)+\lambda d_{2}\left(s^{t}\right)+b_{1}\left(s^{t-1}\right) R\left(s^{t-1}\right) \\
& c_{2}\left(s^{t}\right)+b_{2}\left(s^{t}\right) \leq l_{2}\left(s^{t}\right) w_{2}\left(s^{t}\right)+(1-\lambda) d_{2}\left(s^{t}\right)+\lambda d_{1}\left(s^{t}\right)+b_{2}\left(s^{t-1}\right) R\left(s^{t-1}\right)
\end{aligned}
$$

and initial conditions

$$
b_{i}\left(s^{0}\right) \text { given }
$$

where $d_{i}\left(s^{t}\right)$ denote dividend paid by firms in country $i$. When $\lambda=0$, this setup reduces exactly to the Baxter and Crucini model, in which the only international asset is the non contingent bond. When $\lambda>0$ domestic agents can hold (but not trade) domestic and foreign stocks, and prices in country 1 for the domestic and foreign stock $p_{1}\left(s^{t}\right)$ and $p_{1}^{F}\left(s^{t}\right)$ satisfy

$$
\begin{aligned}
& p_{1}\left(s^{t}\right) U_{1}\left(s^{t}\right)=\beta \sum_{s^{t+1} \mid s^{t}} U_{1}\left(s^{t+1}\right)\left(p_{1}\left(s^{t+1}\right)+d_{1}\left(s^{t+1}\right)\right) \\
& p_{1}^{F}\left(s^{t}\right) U_{1}\left(s^{t}\right)=\beta \sum_{s^{t+1} \mid s^{t}} U_{1}\left(s^{t+1}\right)\left(p_{1}^{F}\left(s^{t+1}\right)+d_{2}\left(s^{t+1}\right)\right)
\end{aligned}
$$

where $U_{1}\left(s^{t}\right) \equiv U_{c}\left(c_{i}\left(s^{t}\right), l_{i}\left(s^{t}\right)\right)$; stock prices in country $2, p_{2}\left(s^{t}\right)$ and $p_{2}^{F}\left(s^{t}\right)$ satisfy similar Euler equations. Note that, because there is no stock trade, the price of, say, stock of the country 1 firm can be different across the two countries. Stock trade is restricted because if it was not, in this simple model, the portfolio held by households in the model would 
be heavily (and counterfactually) biased toward foreign assets (see Baxter and Jermann, 1997), and thus one would have to impose some additional cost of holding foreign assets. Imposing an exogenous share of foreign stocks $\lambda$ in the household portfolio is a very simple (albeit crude) way of doing so; also by varying $\lambda$ we can evaluate the impact of international diversification on the relation between NFA and volatility.

Competitive firms in each country own the capital stock installed in their country $k_{i}\left(s^{t}\right)$, hire labor to operate a Cobb-Douglas technology and solve the following problem

$$
\begin{aligned}
& \max _{l_{i}\left(s^{t}\right), k_{i}\left(s^{t}\right), x_{i}\left(s^{t}\right)} \sum_{t=1}^{\infty} \sum_{s^{t}} d_{i}\left(s^{t}\right) Q_{i}\left(s^{t}\right) \\
& \text { s.t. } \\
& d_{i}\left(s^{t}\right)= A_{i}\left(s^{t}\right) l_{i}^{1-\alpha}\left(s^{t}\right) k_{i}^{\alpha}\left(s^{t-1}\right)-w_{i}\left(s^{t}\right) l_{i}\left(s^{t}\right)-x_{i}\left(s^{t}\right) \\
& k_{i}\left(s^{t}\right)=(1-\delta) k_{i}\left(s^{t-1}\right)+x_{i}\left(s^{t}\right)-\phi k_{i}\left(s^{t-1}\right)\left[\frac{x_{i}\left(s^{t}\right)}{k_{i}\left(s^{t-1}\right)}-\delta\right]^{2} \\
& k_{i}\left(s^{0}\right) \text { given }
\end{aligned}
$$

where $Q_{i}\left(s^{t}\right)$ are state contingent prices used by firms to evaluate dividend payments in state $s^{t}, A_{i}\left(s^{t}\right)$ is a country-specific total factor productivity shock which follows an exogenous process with time varying volatility (the process will be specified below), $\alpha$ is a constant parameter determining the relative importance of capital and labor in production, $x_{i}\left(s^{t}\right)$ represent investment, $\delta$ and $\phi$ are fixed parameters that determine the rate of capital depreciation and the size of capital adjustment costs, respectively. Notice how the statecontingent consumption prices $Q_{i}\left(s^{t}\right)$ affect firms decisions regarding how to divide earnings between investment and dividend payments.

For the reminder of the paper

$$
Q_{i}\left(s^{t}\right)=\beta^{t} \pi\left(s^{t}\right) U_{c}\left(c_{i}\left(s^{t}\right), l_{i}\left(s^{t}\right)\right)
$$

i.e. domestic firms use the stochastic discount factor of the representative domestic household to price dividends. This assumption is a natural one when ownership of the firm of a country is concentrated in that country. When ownership of the domestic firm is internationally dispersed it is possible to make different assumption about $Q_{i}\left(s^{t}\right)$, as foreign and domestic consumers may value differently dividend payments in a given state. ${ }^{7}$

\footnotetext{
${ }^{7}$ One possibility is to assume that $Q_{i}\left(s^{t}\right)$ is a weighted average of the stochastic discount factors of
} 
An equilibrium for this economy is defined as a collection of mappings for prices

$w_{i}\left(s^{t}\right), r_{i}\left(s^{t}\right), p_{i}\left(s^{t}\right), p_{i}^{F}\left(s^{t}\right), R\left(s^{t}\right), Q_{i}\left(s^{t}\right)$, exogenous processes $A_{i}\left(s^{t}\right)$ quantities $c_{i}\left(s^{t}\right), x_{i}\left(s^{t}\right), k_{i}\left(s^{t}\right)$, bond choices $b_{i}\left(s^{t}\right)$, and international portfolios $\lambda$ such that, when consumers and firms take prices and exogenous processes as given, the quantities and bond choices solve their optimization problems, and such that the markets for consumption/investment goods, capital, labor, and bonds clear in each country, in each date $t$ and in each state $s^{t}$. An important quantity is net foreign asset to GDP ratio for country 1, which is defined as

$$
N F A_{1}\left(s^{t}\right)=\frac{\lambda\left(p_{1}^{F}\left(s^{t}\right)-p_{1}\left(s^{t}\right)\right)+b\left(s^{t}\right)}{y\left(s^{t}\right)}
$$

Note that when $\lambda=0$ NFA only depend on bond position, however when $\lambda>0$ the net foreign asset position of a country depends on stock prices movements as well.

\section{Results}

This section uses the model just described to analyze the following issues:

i) Section 4.2 analyzes the response of several macro variables to shocks to the volatility of business cycles. In particular we will focus on how a shock to the volatility of a country affects its net foreign asset position.

ii) Section 4.3 assesses whether the model can replicate the relation between volatility and net foreign asset position documented in the data. And, perhaps more importantly, we will use the model as a tool to evaluate the contribution of volatility shocks to the overall volatility of global imbalances.

iii) Section 4.4 evaluates how the impact of volatility shocks on the net foreign asset position depends on structural features of the economy.

Beforing analyzing these issues, section 4.1 briefly discusses the choice of parameter values and the numerical solution of the model.

households in the two countries, where weights are proportional to their ownership share of the firm. We have experimented with this assumption in the version of the model with positive stock holdings and found that it affected our quantitative results very little 


\subsection{Parameters and computation}

In order to solve the models one needs functional form and parameters for the utility function $U(c, l)$, values for the discount factor $\beta$, for the technology parameters $\alpha, \delta$ and $\phi$, the share of foreign stocks held by domestic residents $(\lambda)$ and, most importantly, for the parameters characterizing the process for TFP shocks $A_{i}\left(s^{t}\right)$. The discount factor $\beta$, the capital depreciation rate $\delta$, the share of capital in production $\alpha$ and the capital adjustment $\operatorname{costs} \phi$ are set so that a symmetric equilibrium in the model (i.e. an equilibrium in which both countries face equally volatile shocks) displays an average yearly return to capital of $4 \%$, a yearly average capital to GDP ratio of 2.5 , an average share of GDP going to labor equal to $64 \%$ and an investment series which is about 3 times as volatile as the GDP series. These values are typical for the United States and other major world economies, and the structure of the model allows us to easily and precisely identify the parameters. The functional form and the parameters describing preferences of the representative agents in both countries are obviously important. In the benchmark case utility has the standard Cobb Douglas form

$$
U(c, l)=\frac{1}{1-\gamma}\left[c^{\mu}(1-l)^{1-\mu}\right]^{1-\gamma}
$$

and we set the parameter $\mu$ in order to match a fraction of time spent working equal to $1 / 3$ and the curvature parameter $\gamma$ to 2. Below we will explore more the role of the curvature parameter and of the functional form for utility. For the share of foreign stocks in our baseline case we set $\lambda=0$ (full home bias) and in section 4.4 we experiment with alternative holdings of foreign stocks. The last important input of the model is the stochastic process for TFP shocks, $A_{1}\left(s^{t}\right)$ and $A_{2}\left(s^{t}\right)$. We specify it as a bi-variate autoregressive process of the form

$$
\begin{aligned}
& \log \left(A_{1}\left(s^{t}\right)\right)=\rho_{A} \log \left(A_{1}\left(s^{t-1}\right)\right)+e^{V_{1}\left(s^{t}\right)} \varepsilon_{1}\left(s^{t}\right) \\
& \log \left(A_{2}\left(s^{t}\right)\right)=\rho_{A} \log \left(A_{2}\left(s^{t-1}\right)\right)+e^{V_{2}\left(s^{t}\right)} \varepsilon_{2}\left(s^{t}\right) \\
& V_{1}\left(s^{t}\right)=\rho_{V} V_{1}\left(s^{t-1}\right)+\eta_{1}\left(s^{t}\right) \\
& V_{2}\left(s^{t}\right)=\rho_{V} V_{2}\left(s^{t-1}\right)+\eta_{2}\left(s^{t}\right)
\end{aligned}
$$

where $\rho_{V}$ and $\rho_{A}$ are fixed parameters determining the persistence of $A$ and $V, \varepsilon_{i}\left(s^{t}\right)$ are the innovations to TFP, and $\eta_{i}\left(s^{t}\right)$ are the innovations to the standard deviations of TFP innovations. These standard deviations are time varying, country specific, and equal to $e^{V_{i}\left(s^{t}\right)} \sigma_{\varepsilon}^{2} \cdot \varepsilon_{i}\left(s^{t}\right)$ and $\eta_{i}\left(s^{t}\right)$ are jointly normal with standard deviations (common across 
countries) $\sigma_{\varepsilon}$, and $\sigma_{\eta}$. Finally let $\xi_{\varepsilon}$, and $\xi_{\eta}$ be the correlations between $\varepsilon_{1}$ and $\varepsilon_{2}$, and between $\eta_{1}$ and $\eta_{2}$, respectively. Overall there 6 parameters: $\rho_{A}, \sigma_{\varepsilon}$ and $\xi_{\varepsilon}$ for productivity and $\rho_{V}, \sigma_{\eta}$ and $\xi_{\eta}$ for its volatility. The parameters of the productivity process are standard in the literature (see for example Baxter and Crucini, 1995). Specifically, we set $\rho_{A}=1, \sigma_{\varepsilon}=$ $1 \%$ and $\xi_{\varepsilon}=0.4$; these parameters generate series for de-trended GDP that have volatility, persistence and international correlation that are comparable to what is observed in the data. The parameters for the volatility process are less common and are set as follows. Since the series for relative volatility plotted in Figure 1 all display high persistence, the volatility shock is assumed to follow a unit root, i.e. $\rho_{V}=1$. We then set their correlation to $\xi_{\eta}=0$ and their volatility $\sigma_{\eta}$ so that the model series for relative volatility of GDP growth over 40 quarters windows (computed exactly as in the data in Figure 1) has the same standard deviation as in the data. ${ }^{8}$ Table 3 summarizes the baseline choices of parameter values. In section 4.4 below we discuss how results are affected by some of these parameters.

\footnotetext{
${ }^{8}$ We have experimented with alternative values for $\xi_{\eta}$, the international correlation of volatility shocks. It turns out that as long as $\sigma_{\eta}$ is recalibrated to match relative volatility of GDP growth in the data, results change very little with $\xi_{\eta}$.
} 
Table 3: Baseline Parameter Values

\begin{tabular}{llc}
\hline Name & Symbol & Value \\
\hline \hline Discount Factor & $\beta$ & \\
Utility function & $\frac{1}{1-\gamma}\left[c^{\mu}(1-l)^{1-\mu}\right]^{1-\gamma}$ & \\
\multicolumn{1}{c}{ Consumption share } & $\mu$ & \\
\multicolumn{1}{c}{ Curvature } & $\gamma$ & 0.37 \\
Capital share & $\alpha$ & 2 \\
Depreciation rate & $\delta$ & 0.36 \\
Capital Adjustment Cost & $\phi$ & 0.025 \\
Share of Foreign Stocks & $\lambda$ & 1.4 \\
\multicolumn{1}{c}{ TFP Shocks } & 0 \\
\hline Persistence of productivity & $\rho_{A}$ & 1 \\
Std. dev. of TFP innovations & $\sigma_{\varepsilon}$ & $1 \%$ \\
Correl. of TFP innovations & $\xi_{\varepsilon}$ & 0.4 \\
Persistence of Volatility shocks & $\rho_{V}$ & 1 \\
Std. dev. of Volatility shocks & $\sigma_{\eta}$ & $4.8 \%$ \\
Correl. of Volatility Shocks & $\xi_{\eta}$ & 0 \\
\hline \hline
\end{tabular}

Note finally that, in order to capture the effects of changes in volatilities, decision rules have to be computed using (at least) third order approximation methods, as the third order is necessary to capture the impact of changes of volatility of shocks on agents decision rules. An additional advantage of using third order approximation is that equilibrium net foreign asset position is stationary, and there is no need of using ad-hoc stationarity inducing techniques (as in Schmitt-Grohe and Uribe, 2003), which, as discussed recently by De Groot, Durdu and Mendoza (2014), can generate solutions that fail to capture the true dynamics of net foreign asset position. The reason why third order approximation of the model guarantees stationarity, is that this solution captures how the precautionary motive changes with the wealth (net foreign asset position) of a country. When the model is solved using first or second order approximation, in response to, say, a mean reverting positive technology shock in country 1 , residents of the country settle to a steady state where they hold a permanently higher level of foreign assets. When the model is solved using third order approximation, this is no longer a steady state, as residents of country 1 have, because of 
the higher wealth, a lower precautionary motive than those in country 2. As a consequence they will decumulate assets until the economy reverts to the original symmetric steady state, where the precautionary motive is equally strong for both countries. Notice however, that even if the net foreign asset position is mean reverting, it exhibits a close to unit-root behavior, and in the long run there will be sequences of shocks that will take it far away from the initial steady state around which the model is solved. In those simulations, one needs to be concerned about the quality of the local approximation, and global solution methods are potentially more reliable. Our analysis (here and in the following section) focuses on short sample realization (max 212 quarters), in which the NFA rarely wanders very far from the steady state and hence the local approximation is likely to be accurate. ${ }^{9}$

\subsection{The impact of volatility changes}

As a benchmark case consider the economy parameterized in Table 3. Figure 2 below shows the 20 years expected responses of key variables to a permanent, unanticipated increase in volatility in country 1 . In particular (see panel a) both countries start with equal standard deviation of TFP innovations (set to $1 \%$, which is the unconditional mean of this standard deviation, as calibrated above) and with other state variables equal to their long run average, including a 0 net foreign asset position. ${ }^{10}$ Then in period 0 volatility of TFP innovation in country 1 increase by $0.5 \%$, which as discussed in section 2 , is a change observed often in the dataset.

Notice in panel (b) how the increase in relative volatility leads to a sizeable net foreign asset accumulation from country 1 and a corresponding imbalance in country 2 . The empirical work in section 2 highlights an association between relative volatility and external imbalances, but does not indicate causation. This result instead suggests a precise causal relation: it is the change in relative volatility that drives the net foreign asset position.

One issue the reader might raise observing panel (b) is whether the net foreign asset position in the long run settles or it continues growing. As discussed above, the third order approximation guarantees that the net foreign asset position eventually settles to a finite positive level. As country 1 accumulates foreign assets, it becomes less concerned about

\footnotetext{
${ }^{9}$ More precisely simulated net foreign asset position is less than $50 \%$ of GDP for more than $90 \%$ of the total simulated observations

${ }^{10}$ Note in this economy certainty equivalent does not hold, hence the long run expected values of variables are in general different from the value of the variables in the deterministic steady state.
} 

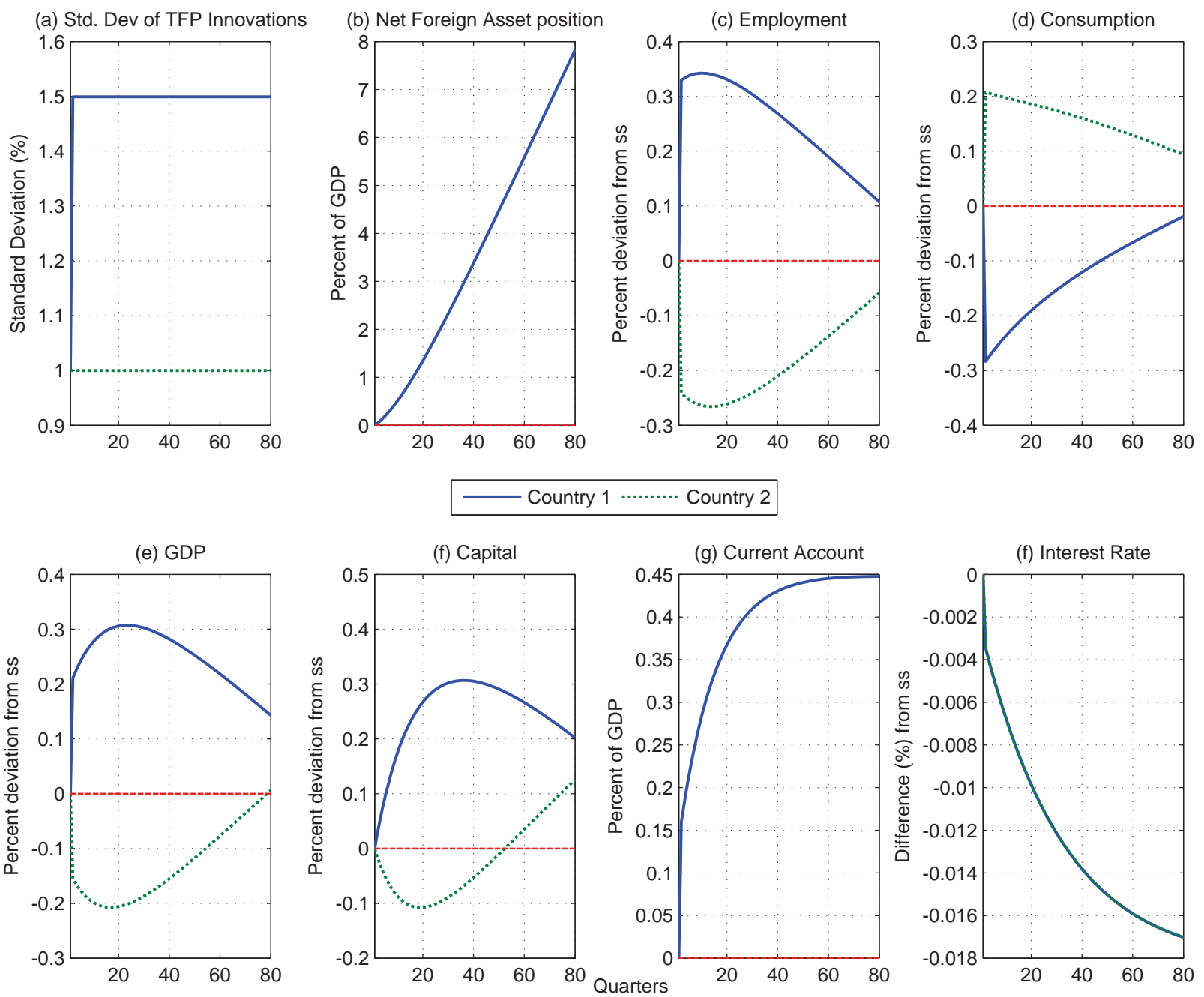

Figure 2: Response to a volatility shock in country 1 (Baseline parameters) 
risk and its precautionary motive weakens. At the same time, country 2 becomes poorer, and its precautionary motive increases. When the net foreign asset position of country 1 becomes so large that these changes in precautionary motives exactly offset the impact of increased risk faced by consumers in country 1 , the net foreign asset position settles to a positive level. ${ }^{11}$

In order to understand the dynamics leading up to the imbalance, panels (c) through (f) report the expected paths of labor, consumption, capital stock, current account and real interest rate. Since consumers in country 1 hold all claims to country 1 GDP, an increase in volatility increases their income risk and their precautionary saving motive. This effect makes them more "patient" by effectively changing their "risk adjusted" rate of time preference. Since there is no similar effect in country 2, the equilibrium interest rate on international bonds (which before the shock was equal to the reciprocal of the common "risk adjusted" discount factor) falls now in between the reciprocal of the two different discount factors; as a consequence consumption of agents in country 1 will fall on impact, because of the increased risk, but drift upward after, due to asset accumulation. Similarly consumption in country 2 will raise on impact (dur to the lower interest rates) and drift downward in subsequent periods, because asset decumulation (see panel d). Our assumption on preferences (Cobb-Douglas in consumption and leisure) implies that households desired path of leisure mimics the path of consumption, and thus labor supply and employment in country 1 increase on impact, increasing returns to capital in country 1 and leading to additional capital in country 1, while the opposite happens in country 2 (see panels c and f). In the longer run however the as consumption in country 1 increases, leisure in country 1 also increases, which eventually leads to a reduction in capital invested in country 1 and to the opposite in country 2 .

Two features of the impulse responses in Figure 2 might be less immediate to understand.

The first is the allocation of capital: when volatility in country 1 increases, capital in country 1 becomes more risky (with the same expected return) relative to capital in country 2 , yet panel (f) shows that more capital is allocated (in the short run) to country 1.

The second feature is that an increase in volatility in country 1 leads to a (modest)

\footnotetext{
${ }^{11}$ Net foreign asset position of country 1 converges to a finite positive level because the impulse is a permanent increase in its volatility. When the impulse in volatility is mean reverting, the reduction in the precautionary saving motive induced by the increase in net foreign asset position eventually pushes the net foreign position back toward the initial steady state of 0 .
} 
increase in GDP in country 1 (see panel e), suggesting that volatility/uncertainty is good for growth.

In order to better understand these features, Figure 3 plots the same set of impulse responses as in the previous figure, for a version of the model with different preferences. In particular preferences have the following functional form (usually known as GHH, from the work of Greenwood et al. 1988):

$$
U(c, l)=\frac{1}{1-\gamma}\left(c-\mu \frac{l^{1+\frac{1}{\xi}}}{\left(1+\frac{1}{\xi}\right)}\right)^{1-\gamma}
$$

GHH preferences display no wealth effect in labor supply, and in particular household labor supply does not depend on consumption, but only on the wage. GHH preferences also allow to set the Frisch elasticity of labor supply independently from other parameters, as the Frisch elasticity is exactly $\xi$. The impulse responses in Figure 3 are computed using a risk aversion parameter $\gamma=2$, a parameter $\mu$ so that average time spent working is $1 / 3$ (as in the baseline) and values for the labor elasticity $\xi$ of 0.5 and 1.5, which define the low and high end of the range used in the macro literature.

Notice first that with these preferences the allocation of capital is less puzzling and, for a given $\xi$, country 1 invests less than country 2 (panel f). The behavior of consumption and employment under the two preferences (panels c and d in Figures 2 and 3) explains why this is the case. Under both preferences the increase in risk induce a fall in consumption in country 1 and, through the fall in interest rate, an increase in consumption in country 2 . Under standard preferences, the change in relative consumption induces a change in relative labor supply, which in turn increases the returns to capital and induces more investment in country 1 than in country 2. Under GHH preferences, the change in relative consumption does not induce a change in relative labor supply, hence returns to capital in country 1 are lower (relative to the standard preferences) and country 2 invests more than country 1. Therefore, the labor supply response is an important factor in understanding the relative capital allocation across countries.

Regarding the second feature, in this setting more volatility leads to growth for two reasons. The first is simply that more risk increases the precautionary motive, which in turn leads to more capital accumulation, and growth. The second mechanism stems from the 

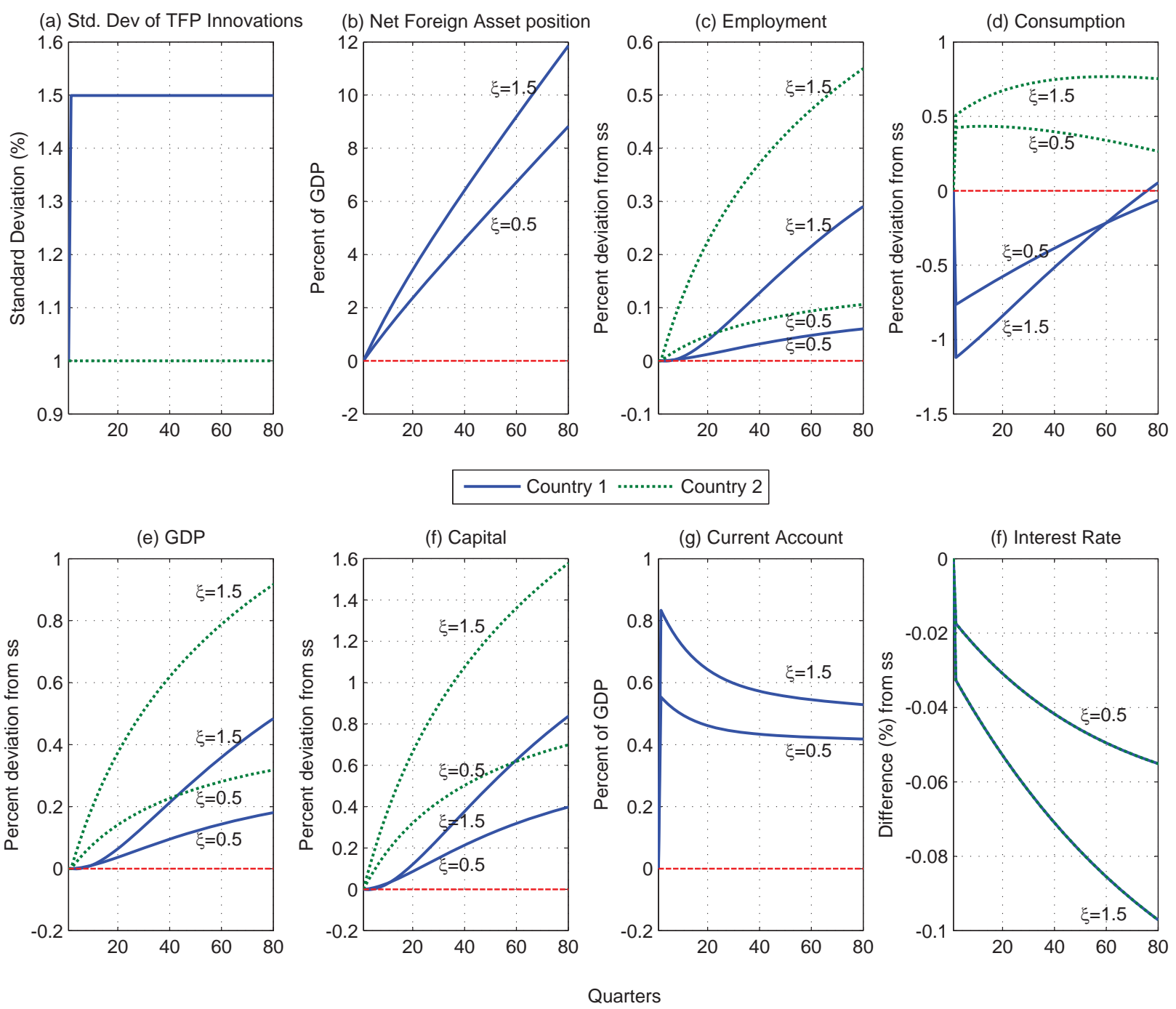

Figure 3: Response to a volatility shock in country 1 (GHH preferences) 
fact that volatility of shocks can be beneficial when agents can adjust the supply of factors. ${ }^{12}$ Agents can take advantage of high productivity periods by working harder, while they reduce the negative impact of low productivity periods by enjoying more leisure. These responses imply that labor supply and output are (under certain parameters) convex functions of productivity and thus their expected values are increasing in volatility. This mechanism is operating in our economy as panels (c) and (e) of Figure 3 show; when the elasticity of labor supply $\xi$ is higher (and the labor supply more convex) expected labor supply and output in country 1 increase by more, in response to the same volatility shock. ${ }^{13}$

Overall our model, due to the effects described above, predicts that a large increase in volatility has a positive but fairly small effect on growth: in response to a $50 \%$ increase in volatility in country 1, GDP in that country increases by $0.5 \%$ at the most. Although some researchers might not find this an empirically plausible feature of the model, we believe that it is not essential for generating a positive relation between NFA and volatility. We conjecture that, had the model included a mechanism through which volatility affect negatively growth (as in, for example, Basu and Bundick, 2012 or Bloom et al., 2012), volatility could possibly have a even stronger effect on imbalances. If, for example, a volatility increase causes a big drop in investment, that would further reduce foreign borrowing and increase accumulation of foreign assets in that country and strengthen the positive relation between volatility and imbalances

To summarize the section, the impulse responses suggest that volatility has, through precautionary behavior, an impact on net foreign asset position: panels (b) of Figures 2 and 3 suggest that response of net foreign asset position is positive and economically relevant for a variety of specifications.

\subsection{Quantitative assessment}

The previous section has shown that in the context of this model, changes in volatility do induce changes in net foreign asset position. This section will show that the model can generate a relation between the two variables that is quantitatively comparable to the association observed in the data. This provides support to the main hypothesis of this

\footnotetext{
${ }^{12}$ This mechanism has been first highlighted by Oi (1961). Cho and al. (2014) and Heathcote and al. (2013) have recently discussed its relevance in macro models.

${ }^{13}$ Note that high elasticity implies a stronger factor and output response in country 2 as well. Even though country 2 does not face more volatile productivity, it can take advantage of the more volatile equilibrium interest rates.
} 
paper that changes in volatility are an important driver of external imbalances. Moreover, this finding allows us to use the model to assess in a more structural fashion the fraction of volatility of global imbalances that is explained by differences in country specific volatility. The simulation procedure is as follows. We first simulate our two country model for 212 periods (the maximum length of the actual series in the dataset) for 20 times (the number of countries). We keep innovations to productivity hitting country 2, which is the model analogue of the rest of the world, the same across the 20 simulations of the two-country model. For country 1, histories of innovations change in each country pair simulation. For each simulation, relative volatility of GDP growth is computed as the difference between the standard deviation of GDP growth in country 1 and country 2 (over the fixed window width). Then all series concerning country 2 are dropped, so that we are left with time series for 20 different artificial countries, each hit by different shocks, but each facing the same partner. These 20 artificial countries are the model analogue of the dataset used in the empirical analysis, so the artificial dataset can be used to compute all the statistics computed on the actual data, including the regressions of NFA on volatility. This procedure is then repeated 10 times, so to obtain 10 versions of the artificial world economy. All model statistics are computed as averages of the corresponding statistics across 10 different repetitions of the artificial "world" economy. ${ }^{14}$ We now describe our results, which are presented in Table 4. The first column of the table reports statistics computed on data, the second reports the same statistics computed on artificial data generated by the model, simulated using the baseline parameters from Table 3, and the last column reports statistics from a version of the model without volatility shocks. The first row reports average volatility of GDP growth across countries, to check that our model generates plausible business cycles. Both versions of the model generate volatility of business cycles that is comparable to what is observed in the data. ${ }^{15}$ The second and third row report standard deviations of our two variables of interest computed over 10 years windows: the relative volatility of GDP growth, our measure of time varying risk/uncertainty and the standard deviation of NFA, our measure of global imbalances. The last four rows report the regression coefficients obtained regressing NFA on relative volatility, where these variables are computed on different time windows.

Not surprisingly the model with volatility shocks matches exactly the relative volatility

\footnotetext{
${ }^{14}$ We experimented with shortening (to 106 periods) and lengthening (to 424 periods) the sample of each country pair simulation, and with increasing the number of repetitions of the "world economy"; quantitative results were largely unaffected.

${ }^{15}$ Both versions of the model also generate volatility of investment, consumption and net exports and co-movement of these variables with GDP in line with data.
} 
in the data, as the standard deviation of volatility shocks (the parameter $\sigma_{\eta}$ ) is calibrated to match this moment. Notice also how the model generates a standard deviation of the NFA to GDP ratio of $17.1 \%$, which is comparable, although a bit higher, than what is observed in the data (14.3\%). Most interestingly for our purposes, the model generates a positive association between relative volatility and NFA, as measured by the positive regression coefficients. The coefficients are increasing with the length of the window (from 6.5 to 10.5$)$ and the coefficient of NFA on lagged volatility is higher than the coefficient on contemporaneous volatility $(13.6 \mathrm{v} / \mathrm{s}$ 7.7). These two features of the model indicate that in the model volatility affects NFA by inducing more accumulation over time, as it was suggested by the impulse responses. The fact that these two features of the regression coefficients in the model also appear in the data, indicate to us that accumulation of NFA due to precautionary reasons in response to higher uncertainty is also happening in the data.

Note that although they display a similar qualitative pattern, the coefficients in the model are lower than the ones estimated in the data, suggesting that some of the association between the NFA and volatility in the data might be driven by factors not captured in our simple model. Possibly a model with a mechanism through which more volatility/uncertaint leads to lower output, could have captured an additional effect of volatility on NFA, and generate coefficients more in line with the data

A final point from the table is that when volatility shocks are shut down (third column of the table) the model generates significantly less volatility in NFA (volatility goes from $17.1 \%$ to $9.9 \%$ ) and NFA are no longer positively associated with relative volatility (the regression coefficients in the third column are all negative). The main conclusion from this is that country specific shocks to volatility/uncertainty are a quantitatively important determinants of the evolution of global imbalances among developed economies. 
Table 4. Quantitative Results: Data and Model

Data Model

Vol. Shocks No Vol. Shocks

\begin{tabular}{lccc}
\hline \hline Business Cycle statistics $^{(a)}$ & & & \\
\hline Std. dev. of GDP growth & $1.14 \%$ & $1.22 \%$ & $1.02 \%$ \\
Std. dev. of Relative Volatility & $0.28 \%$ & $0.28 \%$ & $0.11 \%$ \\
Std. dev. of NFA & $14.3 \%$ & $17.1 \%$ & $9.9 \%$ \\
Regression Coefficients ${ }^{(b)}$ & & & \\
\hline \multirow{2}{*}{5 yrs windows } & 12.8 & 6.5 & -1.96 \\
& $(4.6)$ & & \\
10 yrs windows & 16.4 & 7.7 & -3.61 \\
& $(4.8)$ & & \\
10 yrs windows lagged & 20.7 & 13.6 & -2.54 \\
& $(7.3)$ & & -7.53 \\
20 yrs windows & 20.9 & 10.5 & \\
\hline
\end{tabular}

${ }^{(a)}$ Statistics in the data are averages across countries. Statistics from the model are averages across countries and across the 10 repetitions of the world economy.

${ }^{(b)}$ In all regressions (in the data and in the model) the dependent variable is NFA and the independent variable is relative volatility. All regressions include time and country fixed effects, and controls for average growth over the window. Regression coefficients from the model are averages across the 10 repetitions of the world economy.

A final note on the quantitative properties of the model regards its (in)-ability to generate sizeable equity premia and volatility of stock prices. There is a literature (see Bansal et al. 2005, or Lettau et al. 2008, among others) suggesting that changes in macroeconomic risk are an important determinant of stock prices and stock returns. We have computed equity premia and volatility of stock prices for our baseline model, and found them to be an order of magnitude smaller than in the data, so we conclude that our model is not useful for evaluating the effects of volatility on these financial variables. It would be an interesting extension to explore the impact of volatility on NFA in a business cycle model modified to reproduce financial variables (as in, for example, Jermann, 1998). 


\subsection{The role of persistence of shocks, risk aversion and international di- versification}

This section assesses how the main quantitative results regarding the impact of volatility shocks on net foreign asset position depend on our assumptions on parameters, i.e. on the underlying structural features of the economy. In particular it studies how results vary with the persistence of productivity shocks, the persistence of volatility shocks, the degree of risk aversion and finally the degree of international portfolio diversification. As a metric of the impact we report, in Figure 4, the impulse response of net foreign asset position (relative to GDP) to a shock in $V$ that increases the volatility of domestic productivity from $1 \%$ to $1.5 \%$. The thick lines report the response for the baseline parameters (the same response that is plotted in panel (b) of Figure 2), and the other lines report the response under alternative parameterizations. Panels (a) and (b) show that when shocks are less persistent (either $\rho_{A}<1$ or $\rho_{V}<1$ ), then the precautionary accumulation of foreign assets in response to an increase in volatility is much smaller; if $\rho_{A}<1$ shocks themselves are short lived, while if $\rho_{V}<1$ the increase in volatility is short lived. Panel (c) considers alternative values for the curvature parameter $\gamma$ that determines risk aversion of households. The panel shows that as $\gamma$ increases, households are more concerned about increases in volatility and hence increase more foreign assets in response to a given increase in volatility. Overall the three panels suggest that a strong precautionary motive is necessary to obtain a strong response of NFA. In the context of this simple model, a strong precautionary motive is obtained either with highly persistent shocks or with highly risk averse households. Finally the last panel shows how the accumulation of foreign assets changes when agents can hold different share of foreign stocks. The idea is that when, say, domestic agents hold a larger share of foreign stocks, they are less exposed to domestic productivity risk, and hence they need to increase their precautionary balance less in response to an increase in volatility of domestic productivity. The figure shows that this is indeed the case, as when $\lambda$ increases the response of net foreign asset is smaller; quantitatively though, even with substantial diversification (when $\lambda=100 \%$ agents hold only foreign stocks), the response of NFA is large.

\section{Conclusions}

There are two main contributions in this paper. The first is to show that, after controlling for a wide array of factors, country specific uncertainty/volatility is significantly related to the 
(a) Persistence of Productivity, $\rho_{A}$

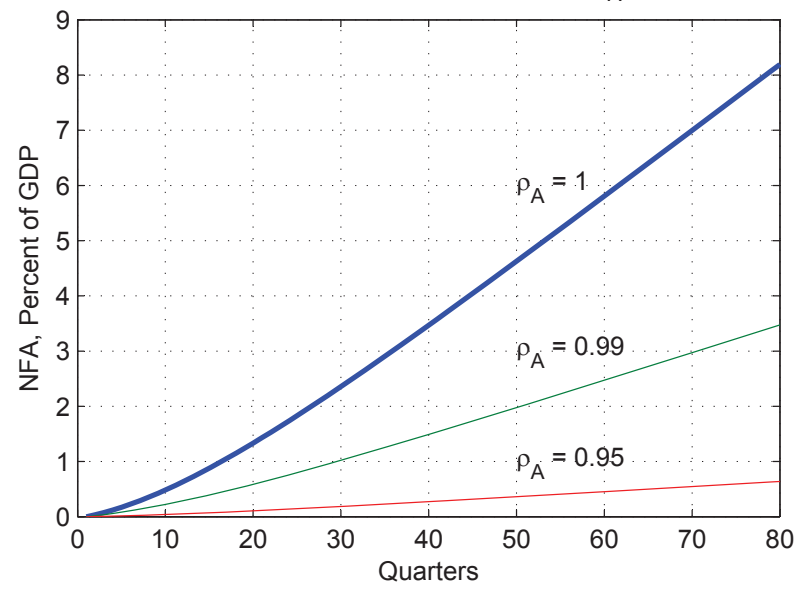

(c) Risk Aversion, $\gamma$

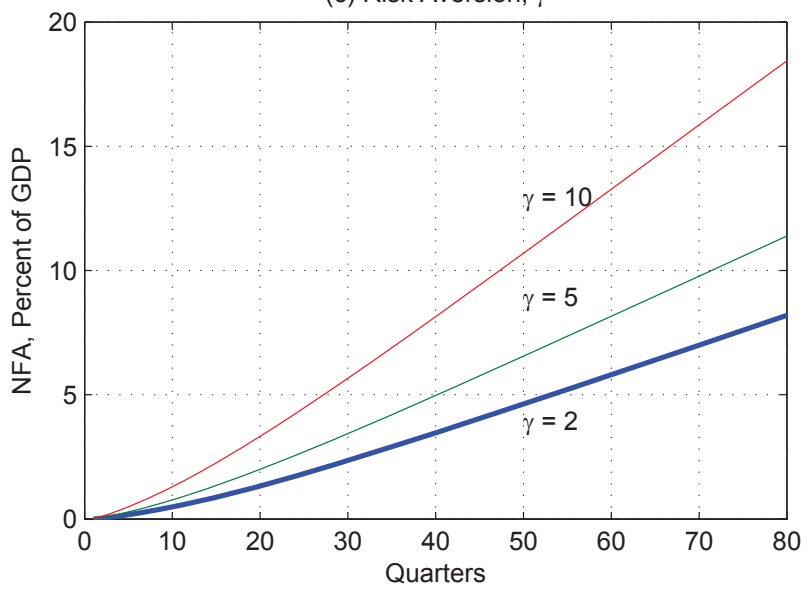

(b) Persistence of Relative Volatility, $\rho_{\mathrm{V}}$

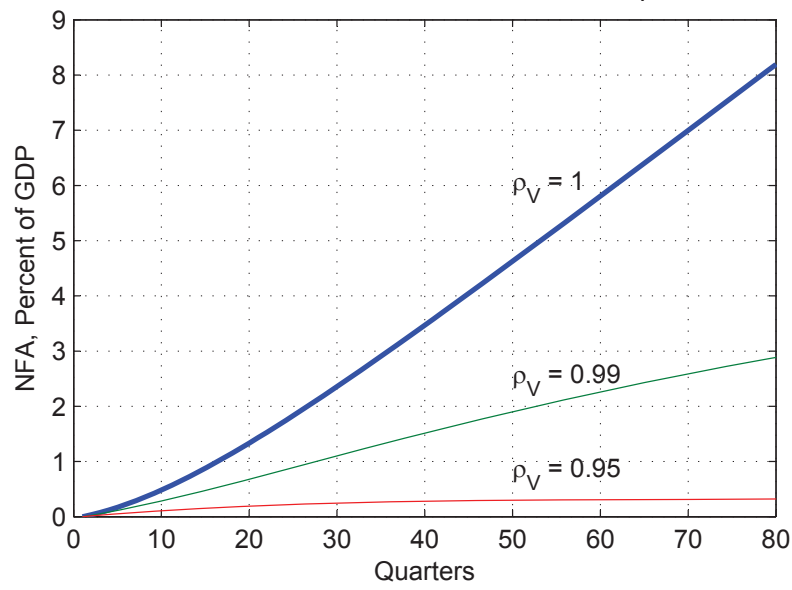

(d) Holdings of Foreign Stocks, $\lambda$

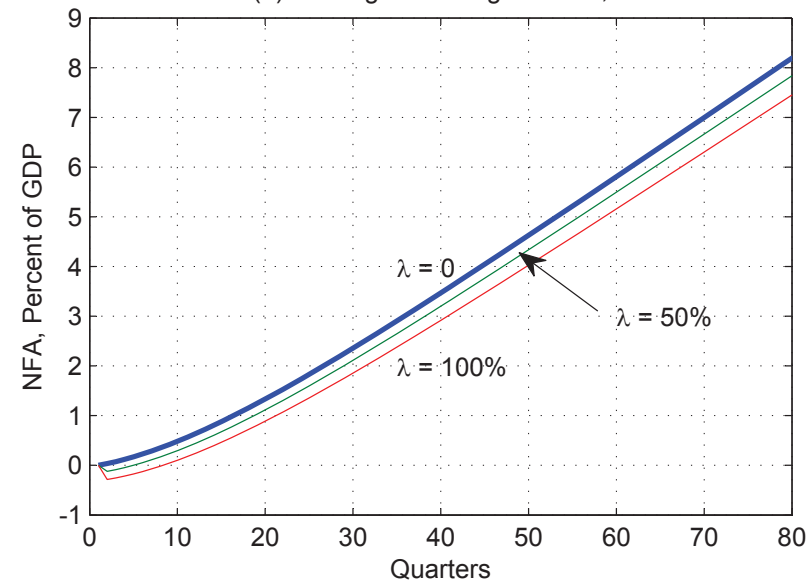

Figure 4: Sensitivity Analysis of Impact of Volatility Shock on Net Foreign Assets 
accumulation of foreign assets in the medium and long run: countries that face an increasing relative macro risk tend to run current account surpluses for a period of time. This relation is economically significant: an increase in volatility (measured as standard deviation of GDP growth) of $0.5 \%$ over a period 10 years, is associated with an increase in net foreign asset position of around $8 \%$ of GDP, over the same period. The second contribution is to show that a standard simple open economy macro model can quantitatively account for a significant part of this relation. The key ingredient is precautionary motive: more macro risk translates into more saving and more saving leads to accumulation of foreign assets. One conclusion that can drawn from these results is that macro uncertainty, as well as features shaping the precautionary motive, should be a major factor to consider when discussing the causes, the sustainability and desirability of observed global imbalances. There are four interesting extensions of this research. The first would involve exploring the fundamental causes of changes in aggregate uncertainty in different countries, which in this paper is modeled as an exogenous process. One leading candidate here is uncertainty about policy, which has been recently emphasized by the work of Baker et al (2013). Second, the standard model used here predicts that an increase in uncertainty leads to a modest increases in growth. In light of the growing literature suggesting that uncertainty appears to be detrimental for growth, it would be interesting to augment our model to include a mechanism that allow for uncertainty to reduce growth. The quantitative section conjectures that doing so would strengthen the link between volatility and NFA, and improve the ability of the model to explain the data. A third direction would be to extend our empirical analysis to emerging markets and assess the role of macroeconomic uncertainty in determining imbalances for those countries. As emphasized by Coeurdacier et al. (2013) emerging markets usually face higher uncertainty that might play an important role in explaining why capital does not flow toward those countries, even when returns to capital are high. A final extension would be to add to our model idiosyncratic risk (as in Mendoza and al. 2009) so to study potential interactions between idiosyncratic and aggregate risk (as in De Santis, 2007). These interactions could be important because, in the presence of large idiosyncratic risk, even small increases in aggregate risk can have a large impact on precautionary motive and therefore external imbalances. 


\section{References}

[1] Arellano Cristina, Yan Bai and Patrick Kehoe (2012) "Financial Frictions and Fluctuations in Volatility", Federal Reserve Bank of Minneapolis Research Department Staff Report 466

[2] Backus, David, Patrick Kehoe, and Finn Kydland (1992), "International Real Business Cycles", Journal of Political Economy, 100, 745-775.

[3] Backus, David, Espen Henriksen, Frederic Lambert and Christopher Telmer (2009), "Current Account Fact and Fiction," NBER Working paper 15525

[4] Baker, Scott, Nicholas Bloom and Steven J. Davis, (2013) "Measuring Economic Policy Uncertainty", Working Paper, Stanford University

[5] Bansal, Ravi, Varoujan Khatchatrian and Amir Yaron, (2005) "Interpretable asset markets?", European Economic Review, 49(3), 531-560,

[6] Barlevy, Gadi (2004), "The Cost of Business Cycles Under Endogenous Growth," American Economic Review, 94(4), 964-990.

[7] Basu, Susantu and Brent Bundick (2012) "Uncertainty Shocks in a Model of Effective Demand", NBER Working Paper 18420

[8] Baxter, Marianne and Mario Crucini (1995), "Business Cycles and the Asset Structure of Foreign Trade", International Economic Review, 36, 821-854

[9] Baxter, Marianne, and Urban Jermann. (1997). "The International Diversification Puzzle is Worse Than You Think." American Economic Review 87(1): 170-80.

[10] Bianchi Javier, Juan Carlos Hatchondo and Leonardo Martinez (2012) "International Reserves and Rollover Risk", NBER Working paper 18628

[11] Blanchard, Olivier (2007), "Current Account Deficits in Rich Countries ", IMF Staff Papers, 54, 191-219

[12] Bloom, Nicholas (2009), "The Impact of Uncertainty Shocks", Econometrica, 77(3), 623-685 
[13] Bloom, Nicholas, Max Floetotto, Nir Jaimovich, Itay Saporta-Eksten and Stephen Terry (2012), "Really Uncertain Business Cycles ", NBER Working paper 18245

[14] Broer Tobias (2012), "Domestic or Global Imbalances? Rising income risk and the fall in the US current account", Working paper, IIES Stockholm

[15] Caballero, Ricardo, Emmanuel Farhi and Pierre-Olivier Gourinchas (2008), "An Equilibrium Model of "Global Imbalances" and Low Interest Rates", American Economic Review, 98(1), 358-393

[16] Chang, Yongsung, Sun-Bin Kim and Jaewoo Lee (2013), "Accounting for Global Dispersion of Current Accounts", Review of Economic Dynamics, 16(3), 477-496

[17] Cho, Jang-Ok, Thomas F. Cooley and Hyung Seok E. Kim (2014), "Business Cycle Uncertainty and Economic Welfare", Working Paper, New York University

[18] Coeurdacier Nicolas, Hélène Rey and Pablo Winant (2013) "Financial integration and growth in a risky world", Working Paper, Sciences Po

[19] De Groot, Olivier, Bora Durdu, and Enrique Mendoza (2014), "Solving DSGE Models with Incomplete Asset Markets: Global vs. Local Methods ", Working Paper, University of Pennsylvania

[20] De Santis, Massimiliano (2007), "Individual Consumption Risk and the Welfare Cost of Business Cycles", American Economic Review, 97(4), 1488-1506

[21] Domeij, David and Martin Flodén (2006), "Population Aging and International Capital Flows ", International Economic Review, 47(3), 1013-1032

[22] Durdu, Bora , Enrique Mendoza and Marco Terrones, (2007), "Precautionary Demand for Foreign Assets in Sudden Stop Economies: An Assessment of the New Merchantilism" Journal of Development Economics, 89, 194-209.

[23] Fernández-Villaverde, Jesús, Pablo Guerrón-Quintana, Juan Rubio-Ramírez and Martín Uribe (2011), "Risk Matters: The Real Effects of Volatility Shocks", American Economic Review, 101(6): 2530-61.

[24] Fogli, Alessandra and Fabrizio Perri (2006), "The Great Moderation and the US External Imbalance", Monetary and Economic Studies, December, 24, 209-225 
[25] Gourio, Francois, Michael Siemer and Adrien Verdelhan (2014), Uncertainty Betas and International Capital Flows, Working Paper, MIT Sloan School of Management

[26] Greenwood, Jeremy, Zvi Hercovitz, and Gregory Huffman, (1988), "Investment, capacity utilization, and the real business cycle." American Economic Review 78 (3), 402-417.

[27] Heathcote, Jonathan, Kjetil Storesletten and Giovanni Violante (2008), "Insurance and Opportunities: A Welfare Analysis of Labor Market Risk", Journal of Monetary Economics, 55, 501-525.

[28] Hur, Sewon and Illenin Kondo (2013), "A theory of rollover risk, sudden stops, and foreign reserves", International Finance Discussion Papers 1073, Board of Governors of the Federal Reserve System

[29] Jaimovich, Nir, and Henry E. Siu (2009), "The Young, the Old, and the Restless: Demographics and Business Cycle Volatility", American Economic Review, 99(3), 80426

[30] Jeanne, Olivier and Romain Ranciáre (2011) "The optimal level of international reserves for emerging market countries: a new formula and some applications", The Economic Journal, 121, 905-930

[31] Jermann, Urban (1998), "Asset pricing in production economies “, Journal of Monetary Economics 41,257-275

[32] Justiniano, Alejandro and Giorgio Primiceri (2008), "The Time Varying Volatility of Macroeconomic Fluctuations", American Economic Review, 98(3), 604-641

[33] Lettau, Martin, Sidney Ludvigson and Jessica Wachter (2008), "The declining equity premium: What role does macroeconomic risk play?", Review of Financial Studies 21 (4), 1653-1687

[34] Lane, Philip and Gian Maria Milesi-Ferretti (2007), "The External Wealth of Nations Mark II: Revised and Extended Estimates of Foreign Assets and Liabilities,1970-2004," Journal of International Economics, 73(2), 223-250 
[35] Mendoza, Enrique, Vincenzo Quadrini and Victor Rios-Rull (2009), "Financial Integration, Financial Development and Global Imbalances," Journal of Political Economy, $117(3), 371-416$

[36] Oi, Walter (1961) "The Desirability of Price Instability Under Perfect Competition", Econometrica, 29(1), 58-64

[37] Prades, Elvira and Katrin Rabitsch (2012), "Capital liberalization and the US external imbalance ", Journal of International Economics 87, 36-49

[38] Ramey, Garey and Valerie Ramey (1995), "Cross-Country Evidence on the Link between Volatility and Growth "American Economic Review, 85(5), 1138-51

[39] Schaal, Edouard (2013), "Uncertainty, Productivity and Unemployment in the Great Recession ", Working Paper, New York University

[40] Schmitt-Grohe, Stephanie, and Martin Uribe, (2003), "Closing Small Open Economy Models," Journal of International Economics, 61(1), 163-185. 